\title{
Behaviour Modification through Guidance and Counselling among Students in Selected Public Universities in Zambia: Is it Possible?
}

\author{
*Abigail Mukuwa Tuchili \\ University of Zambia School of Education, Lusaka, Zambia \\ Dr. Daniel Ndhlovu
}

University of Zambia, Institute of Distance Education, Lusaka, Zambia

\begin{abstract}
Appropriate behaviour is cardinal among people in every community. It is practically fundamental for young people and the youth to exhibit acceptable behaviour and university students are no exception. To attain acceptable behaviour there is need for behaviour modification. This paper is an extract from an on-going PhD study. The study was guided by the objective which sought to establish how guidance and counselling services were used to address deviate behaviour by students in public universities. In order to attain this objective; a descriptive survey design was used, with a sample of 105. In-depth interview guides, focus group discussions and self-administered questionnaires were used to collect data. Thematic analysis and SPSS were used to analyse the data. The study found that students who accessed guidance and counselling services exhibited acceptable behaviour in various aspects of their lives. In conclusion; the paper argues that students who received guidance and counselling services had their behaviours modified. On the basis of these findings, the study recommends that there is need to encourage all students in public universities to access guidance and counselling for them to develop acceptable behaviour.
\end{abstract}

Keywords: Behaviour modification, Guidance and Counselling, deviate, appropriate

\section{INTRODUCTION}

\subsection{Background to the Study}

The need for guidance and counselling is paramount in promoting the wellbeing of an individual as well as groups of people who need to be guided in their interactions in terms of health and the environment, acquiring skills, knowledge, attitudes, just to mention a few. All these can result in emotional strain which impacts individuals' adjustment to life. In order to survive in new environment, students must take responsibility for their actions. Universities and higher education institutions play an essential role in helping students meet the challenge of becoming the world's leading knowledge-based society. The transition to university for many university students has the potential to be stressful requiring the student to make significant adjustments to their personal, social and academic lives. The goal of guidance and counselling is to promote development of the whole individual in order to ensure the student 'flourishes' in their total wellbeing (Corey, Corey and Callahan, 2007). Goal-directed behaviour is thus essential for every human being.

Guidance is therefore, a process that builds up a human character rather than a single event. Similarly, Watts and Kidd (2000:489) define guidance as a "range of processes designed to enable individuals to make informed choices and transitions related to their educational, vocational and personal development". Thus, it can be argued that guidance "involves helping students individually or in small groups in making personal, educational or vocational choices" (Hornby, 2003a:4). Others who have attempted a classification of the term guidance include Thompson and Poppen (1979). They point out a distinction implicit in using the term guidance as a concept, educational construct and educational service. K'Okul (2010) explains that much of the current literature on guidance and counselling emphasises a "whole person" (integrative) approach in addressing the guidance needs of clients. According to Tambuwal (2010), guidance means to direct, pilot, manage, steer, aid, assist, lead and interact; while counselling can be seen as the process by which a person with problems is helped by a 
professional counsellor to voluntarily change his behaviour, clarify his attitude, ideas and goals so that his problems may be solved. From the two definitions, guidance is a combination of services, while counselling is just one service under guidance.

This study strived to show the relationship between guidance and counselling and behaviour modification among students in selected public universities in Zambia. Most of the young people in university are at a crucial development stage in their life, hence it was assumed that access to guidance and counselling would help them to deal with any peer pressure that may lead to any form of deviate behaviour. In the context of the study being reported in this paper, behaviour modification is exhibited by students after accessing the guidance and counselling services as advanced.

\subsection{Statement of the Problem}

Although guidance and counselling is offered to students in educational institutions in Zambia, its effect on shaping behaviour among university students is not known. The purpose of the study therefore, was to establish how guidance and counselling services can be used to address deviant behaviour by students in public universities and thus contribute to behaviour modification.

\subsection{Objective of the Study}

Establish how guidance and counselling services are used to address deviate behaviour by students in public universities.

\subsection{Research Question}

Precisely, the study addressed the following research question: How can guidance and counselling services be used to address deviant behaviour by students in public universities?

\subsection{Significance of the Study}

At the time when it is not known how guidance and counselling can be used to modify behaviour among university students in Zambia's public universities; a study of this nature was significant to fill this knowledge gap.

\subsection{Study Site}

The study sites for this study were: University of Zambia, Copper Belt University and Kwame Nkrumah University.

\subsection{Limitations}

It was problematic to collect information from some target groups who did not feel comfortable to talk about their personal lives. As a result, cautiousness must be exercised when generalising the results of the study.

\section{Methodology}

This study used a descriptive survey design. The study population comprised full time second and third year students in three selected public universities in Zambia. This type of population was chosen because it met the unique characteristics of participants with knowledge about guidance and counselling services offered in the universities.

The sample comprised three (3) Deans of Students' Affairs (DOSA), 12 Counsellors, and 90 students. The total number of respondents was 105. The benchmark for inclusion of this sample was that these Deans were responsible for the students' affairs, while the counsellors were equally responsible for providing the guidance and counselling services to students. The students had lived experiences of using the guidance and counselling services.

Purposive and simple random sampling procedures were used to select the sample from both the students' body and university officials. Kombo and Tromp (2006) state that the power of purposive sampling procedure lies in selecting information with rich cases for in-depth analysis related to the central issue understudy.

Questionnaires, focus group discussion and interview guides were used to collect data. These three sets of tools provided an opportunity for triangulating the findings, an approach which increases 
credibility in the findings (Patton, 2002). As such, the study findings from these three tools are trustworthy. Qualitative data collected were analysed using thematic analysis, while the quantitative data from questionnaires was analysed using SPSS and excel to create pie charts and tables.

\section{FINDINGS AND DISCUSSION}

\subsection{Behaviour Modification}

The results in the study reveal that guidance and counselling services offered in the public universities helped to address deviate behaviour of students. Based on the results, it was concluded that students had their behaviour shaped positively after accessing guidance and counselling services. The results from the study further indicate that students' behaviour was modified positively after accessing guidance and counselling. This was based on the results from interviews, focus group discussions and questionnaires. Below are some extracts from interviews and focus group discussions.

\subsubsection{During the Interviews Some Deans Said}

'Counsellors are trained to handle students who abuse drugs and exhibit other unwanted behaviour and there has been a change among students who sort guidance and counselling'. Another dean stated:" Some bad vices such as abuse of alcohol, and just bad elements in behaviour are addressed through guidance and counselling'.

\subsubsection{While Another Dean Stated}

'sure indeed, deviate behaviour in some students is definitely addressed when they receive counsel' some are too young and due to peer pressure find themselves in trouble so guidance and counselling helps to address the deviate behaviour'. This finding is in line with previous findings by Nyaga (2011) whose study revealed that guidance and counselling provision had an effect on performance of students who received the service and also on other social competencies.

\subsubsection{Some Statements from Counsellors 'Questionnaires Indicated}

'Students that find themselves in trouble are counselled and guided on how to manage pressure of campus life, therefore, deviate behaviour is somewhat addressed. Further other counsellors indicated: Unwanted negative effects of behaviour is surely contained through guidance and counselling; 'If this institution did not offer guidance and counselling, we would witness more cases of deviate behaviour, you know our numbers have increased and ages of students dropped, we have younger ones than before. It is counselling that helps address this'. 'Deviate behaviour is surely minimised.' One extract from a counsellor sums it all in the following statement: A: 'access to GCS encourages positive acceptable behaviour among students and helps to cognitively reconstruct their thinking'. These findings are in agreement with Chireshe (2006), Gatua et al (2015) which showed in their studies that behaviour of students can be changed positively through guidance and counselling provision.

\subsubsection{Some Students During Focus Group Discussions Said}

'After being guided done takes the right decisions'. Other students said: 'Even when one is in trouble we receive guidance from counsellors and DOSA,' The researcher is of the view that guidance and counselling services on the other hand were vital because they helped the students to cope with life challenges in the university setting. The results of the study appear to indicate that guidance and counselling services in universities have a significant effect in development of students' academic, social and personal competencies. This is supported by past research by Biswalo (1996) that the spirit of universities to plan and utilise guidance and counselling services in effective development of the students various competences was evidently strong. Other studies that support this finding are those done by Samoei (2012), Chepkemei (2014) and Nyaga et al (2014). Therefore, since effective guidance and counselling services in universities have been known to significantly enhance the development of students' academic, social and personal competences, it is safe to conclude that guidance and counselling can be used to shape behaviour of students.

This is also agreed by Chireshe, (2006), who indicates that access to guidance and counselling provision helps students to enhance their performance. The researcher also found out that most students revealed that their performance improved, while their behaviour was positively shaped or 
modified due to access of the guidance and counselling services. The researcher is of the view that guidance and counselling provision has a positive effect on how to nurture students who have varying abilities, capacities, interests and unlimited potential; and to prepare these individuals to become effective functioning members of their changing societies. As regard to general misbehaviour, when a student is counselled they change to acceptable behaviour as they are reminded on consequences and to concentrate on academic work.

Allen (2002) depicts guidance and counselling as an ultimate icon that addresses students' behavioural content, taking into account context, global issues, local priorities, building moral capacities based on rational decision-making, social tolerance, environmental stewardship, adaptable student force and quality of life. The researcher argues that guidance and counselling would surely improve exhibited behaviour by students in public universities. This is confirmed by data from interviews and focus group discussions and also from counsellor responses.

\subsection{Effectiveness of Guidance and Counselling in Shaping Students' Behaviour}

The figure below shows that $92 \%$ of the 90 students spoke in the affirmative that guidance and counselling was effective in shaping the behaviours of students, whereas only $8 \%$ said it was not. The details can be seen in figure 1 .

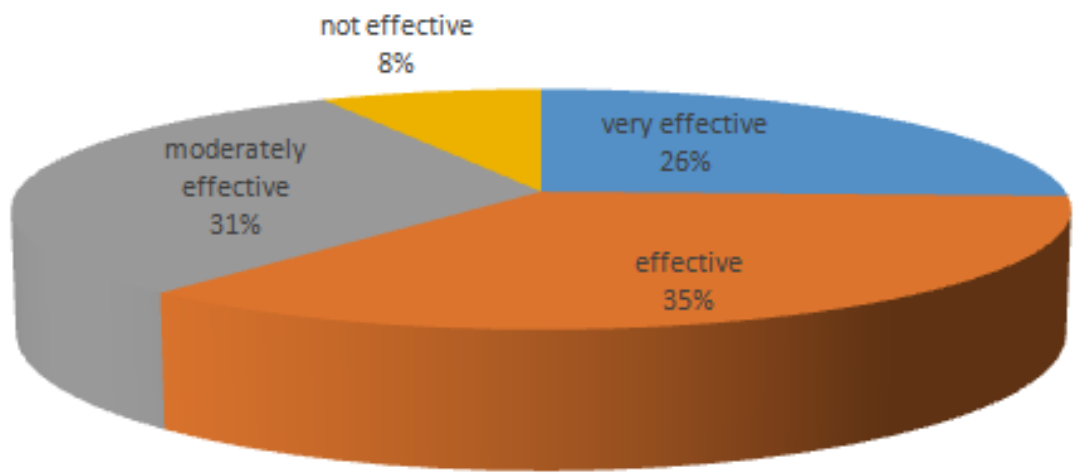

Figure1. Students' Rating of GCS in Modifying their Behaviour

Based on this revelation, it is argued that guidance and counselling effectively shape students' behaviour. Studies by Chireshe, (2006); K'okul (2010) and Nyaga (2011) also state that guidance and counselling was useful in shaping behaviour of students and addressing deviate behaviour among students.

\subsection{How Guidance and Counselling Helped to Modify Students' Behaviour}

The study established that $87 \%$ of the 90 students who participated in the study said that guidance and counselling services were very effective in helping them to avoid taking part in demonstrations, whereas $13.3 \%$ said the services were not effective to assist them to avoid taking part in demonstrations. Details can be seen in figure 2.

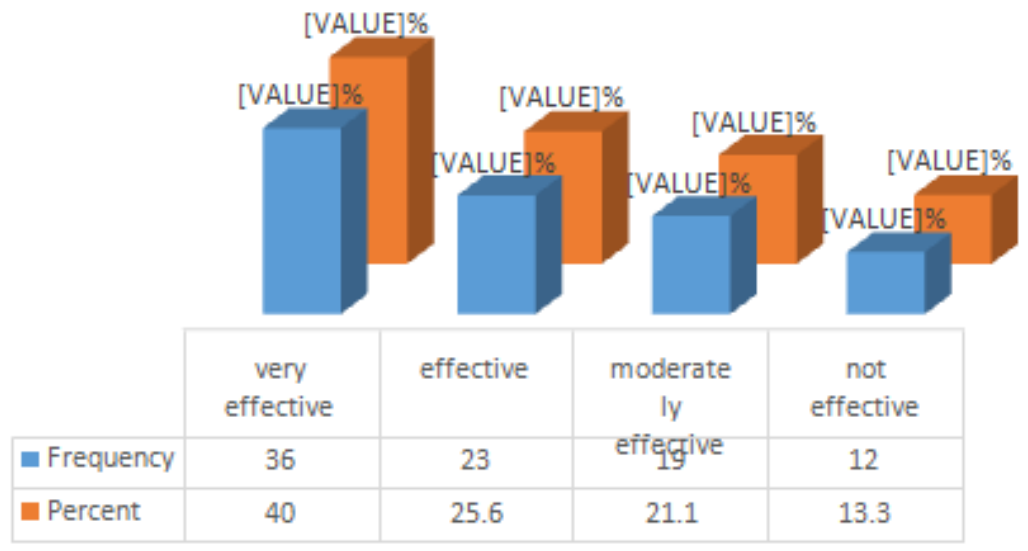

Figure2. Students' Responses in Avoiding Taking Part in Riots 
These results therefore, seem to suggest that guidance and counselling services helped to modify behaviour of students. There is truth in these findings in those similar findings by K'okul (2010) whose study among Kenyan university students revealed that guidance and counselling assists to minimise riots and shape students' behaviour. These results can therefore be relied upon. Other studies that show that behaviour can be modified and shaped by accessing guidance and counselling are those by Samoei (2012) and Gatua et al (2015). The researchers thus argue that guidance and counselling can be used address deviate behaviour in students.

Guidance and counselling services also helped students to balance between academic and extracurriculum activities. Figure 3 below shows that $91.1 \%$ of the students stated that the guidance and counselling services assisted them to balance between academic and extra-curricular activities while $8.9 \%$ said the services were not effective.

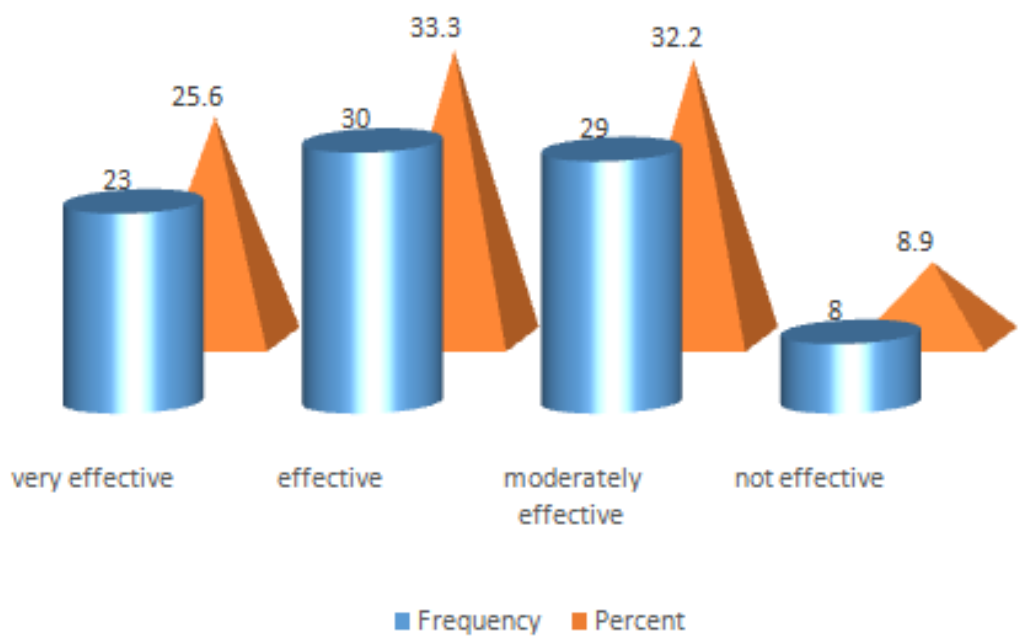

Figure3. Balancing between Academic and Extra-Curriculum Activities

It can therefore be argued that guidance and counselling can be used to modify students' behaviour. Similarly, Nyaga (2011), Nyaga et al (2014) and Chepkemei (2014) found that guidance and counselling contributed to behaviour change among students. These studies further revealed that student's competencies were enhanced through accessing of guidance and counselling services.

\section{CONCLUSION AND RECOMMENDATIONS}

\subsection{Conclusion}

Based on the study findings, it can be concluded that guidance and counselling services can enhance development of students' holistic wellbeing and skills in public universities in Zambia. Students, counsellors and DOSAs all acknowledged that guidance and counselling can be used to enhance positive behaviour in students and consequently shape the behaviour positively. It may also be concluded that if all students accessed guidance and counselling services, they would be a general improvement in their performance; and how they would handle the social and academic challenges encountered through the choices they make and demands of everyday life.

\subsection{Recommendations}

Based on the findings of the study, it is recommended that:

1. Since guidance and counselling is a viable tool for shaping and modifying student's behaviour, it should be offered to all students in public universities.

2. DOSAs and counsellors should encourage all students in public universities to access guidance and counselling services to enhance holistic their development.

3. In order to address shortage of manpower, universities must increase the number of counsellors in all public universities. This will provide an opportunity for more students to access the service. 


\section{REFERENCES}

[1] Allen, S. (2002). Looking for learning in visitor talk: A methodological exploration. Learning Conversations in Museums. G. Leinhardt, K. Crowley and K. Knutson. Mahwah, Lawrence Erlbaum Associates: 259-303.

[2] Biswalo, P.M. (1996). Guidance and Counselling in Divers African Contexts. Dares Salaam: University Press.

[3] Chatterjee, P. \&Canda, E. R. (2006). Contemporary human behaviour theory: A critical perspective for social work. Pearson: USA

[4] Chepkemei, M. (2014).Role Of Guidance and Counselling on Students' Discipline in Boarding Secondary Schools in Ole Ankale Zone, Narok Central Division in Narok North District Kenya. Unpublished Post Graduate Diploma Document. Nairobi: University Of Nairobi.

[5] Chireshe, R. (2006). An Assessment of the effectiveness of school Guidance and Counselling Services in Zimbabwean secondary Schools. Doctoral Dissertation: University of South Africa.

[6] Cresswell, J. W., \& V. L. Plano Clark. (2007). Designing and Conducting Mixed Methods Research. Thousand Oaks, CA: Sage Publications.

[7] Corey, G., Corey, M. S., \&Callanan, P. (2007). Issues and ethics in the helping professions ( $7^{\text {th }}$ ed.). Belmont, CA: Brooks/Cole-Thomson.

[8] Gatua, D. M. et al (2015). Impact of Guidance and Counselling Services on Students' Behaviour Modification between Selected Public Urban and Rural Secondary Schools in Rift Valley Province, Kenya. Research on Humanities and Social Sciences ISSN (Paper)2224-5766 ISSN (Online)2225-0484 (Online) Vol.5, No.19, 2015.

[9] Gibson, R. L. and Mitchell, M. H. (2007). Introduction to Guidance and Counselling. $7^{\text {th }}$ ed. New York:Macmillan

[10] Halim, A. O. (1999). Guidance and Counselling in Malaysia. Kota Kinabalu: University MalaysiaSabah

[11] Hornby, G. S. (2003a). Generative Representations for Evolutionary Design Automation. Ph.D. thesis, Michtom School of Computer Science, Brandeis University, Waltham, 1"MA.

[12] Kombo, K. D. and Tromp, L. A. (2006). Proposal and Thesis Writing: An Introduction Nairobi: Pauline Publications Africa.

[13] K'okul Florence S. A. (2010) Perceptions of Students On The Status Of Guidance and Counselling In Selected Universities In Kenya For Minimizing Student Riots Unpublished PhD Thesis, Kenyatta University: Nairobi.

[14] Ministry of Education (1996). Educating Our Future: National Policy on Education, Lusaka: ZEPH.

[15] Ndhlovu, D. (2015). Theory and Practice of Guidance and Counselling for Schools and Colleges. Lusaka: University of Zambia Press.

[16] Nyaga, K. V. (2011). Effectiveness of Guidance and Counselling Services and Development of Students' Academic, Social and Personal Competencies in Public and Private Universities in Kenya: Doctoral Dissertation, MeruChuka University College.

[17] Patton (2002), Patton, M. Q. (2002). Qualitative evaluation and research methods (3rd ed.). Thousand Oaks, CA: Sage Publications, Inc.

[18] Samoei, W. K. (2012)The Role Of Guidance and Counselling in Management of Student Discipline in Secondary Schools in Londiani District, Kericho County, Kenya. Unpublished MA Dissertation: Kenyatta University

[19] Tambuwal, M.U. (2010). Organizing and administering guidance and counselling programme at the elementary school level for effective performance. A Paper Delivered at 4 Day Workshop for Para-Counselling Officers by the SUBEB in Collaboration with SSCOE, Sokoto

[20] Thompson, C. and Poppen, W. (1979). Guidance Activities for Counsellors and Teachers. Belmont, California: Wadsworth.

[21] Tuchili, A. M. (2008). Evaluation of school guidance and counselling services provision in Selected Schools in Lusaka District. Unpublished MA. Thesis. UNZA: Lusaka.

[22] Watts, A. and Kidd, J. (2000). Guidance in the United Kingdom: Past, Present and Future. British Journal of Guidance and Counselling, Vol. 28, (4), pp 485- 502. 
Behaviour Modification through Guidance and Counselling among students in Selected Public Universities in Zambia: Is it possible?

AUTHORS' BIOGRAPHY

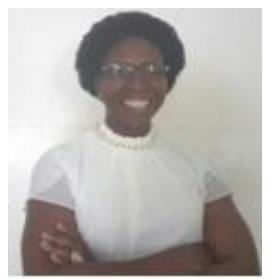

Abigail Tuchili, is an Educational Psychologist and a $\mathrm{PhD}$ candidate in the School of Education, Department of Educational Psychology, Sociology and Special Education (EPSSE) at the University of Zambia.She is currently serving as Senior Curriculum Specialist at the Curriculum Development Centre (CDC) in the Ministry of General Education (MOGE) - Zambia. She has over 10 yearse experience in the field of curriculum design and development and over 13 yearse as a teacher. Her $\mathrm{PhD}$ thesis is about Role ofguidance and counselling in shaping

students' behaviour in selected public universities in Zambia'. Abigail has participated in various National and International fora on guidance and counselling. She is currently a member of the Psychology Association of Zambia (PAZ) and National Counselling and Guidance Association of Zambia (NACGAZ); and part time lecturer of Educational Psychology at the University of Lusaka. Her latest publication of January 2017 titled: Shaping Behaviour among Students in Zambia's Public Universities: Can Guidance and Counselling be Useful? In International Journal of Humanities Social Sciences and Education (IJHSSE) Volume 4, Issue 1, January 2017, PP 48-54 ISSN 2349-0373 (Print) \& ISSN 2349-0381 (Online) http://dx.doi.org/10.20431/2349-0381.0401006 www.arcjournals.org

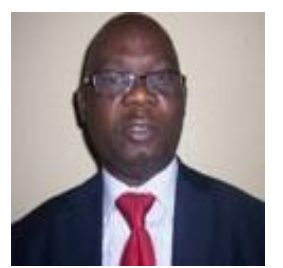

Dr. Daniel Ndhlovuis, a Senior lecturer in the Department of Educational Psychology, Sociology and Special Education at the University of Zambia. He holds a doctoral degree in Special Education, Master's degree in Education and Bachelor's degree in Special Education from the University of Zambia. In addition to lecturing, he has held senior administrative positions at the University of Zambia which includes Assistant Dean Postgraduate in the School of Education and Assistant Director Postgraduate in the Institute of Distance Education. He has over 29 years teaching and lecturing experience at secondary school and tertiary levels of education. Dr. Ndhlovu is also the current president of the National Counselling and Guidance Association of Zambia (NACGAZ). He has done numerous research activities and publications in local and international refereed journals. His latest publication is of 2017 and is titled Shaping Behaviour among Students in Zambia's Public Universities: Can Guidance and Counselling be Useful?This isauthored by Tuchili, M. A. and Daniel Ndhlovu.International Journal of Humanities Social Sciences and Education (IJHSSE) Volume 4, Issue 1, January 2017, PP 48-54 ISSN 2349-0373 (Print) \& ISSN 2349-0381(Online) http://dx.doi.org/10.20431/2349-0381.0401006 www.arcjournals.org 